\title{
FORTIFICATION OF DAMAGED ASPHALT PAVEMENTS WITH CEMENT CONCRETE SLABS REINFORCED WITH NEXT-GEN BARS - PART I: LABORATORY STUDY
}

\author{
PIOTR RADZISZEWSKI ${ }^{1}$, WIOLETTA JACKIEWICZ-REK ${ }^{2}$, MICHAŁ SARNOWSKI ${ }^{3}$, \\ MAREK URBAŃSKI ${ }^{4}$
}

\begin{abstract}
Over the course of operation, asphalt road pavements are subjected to damage from car traffic loads and environmental factors. One of the possible methods of strengthening damaged asphalt pavements may be the application of an additional rigid layer in the form of a cement concrete slab with continuous reinforcement. This paper presents a material-technological and structural solution for composite pavement where a cement concrete slab with continuous HFRP bar reinforcement is used for strengthening. Based on laboratory tests, the serviceability of composite bar reinforcement of rigid pavement slabs was shown. A design for strengthening asphalt pavement with a concrete slab with steel bar and corresponding HFRP bar reinforcement was developed. The composition of a pavement cement concrete mix was designed, and experimental sections were formed. Based on laboratory tests of samples collected from the surfaces of experimental sections and the diagnostic tests carried out in "in situ" conditions, the authors will try, in the nearest future (Part II: In situ observations and tests), to confirm the effectiveness of strengthening asphalt pavements with cement concrete slabs with HFRP components.
\end{abstract}

Keywords: strengthening, HFRP bars, continuous reinforcement, cement concrete pavements, damaged asphalt pavements.

\section{INTRODUCTION}

The most commonly used road pavement construction method in Poland is asphalt technology. Asphalt pavements under operation are damaged under the impact of loads from car traffic and the influence of environmental factors. One of the possible ways to strengthen damaged asphalt pavements may be through the application of an overlay in the form of a relatively thin, rigid

\footnotetext{
${ }^{1}$ Prof., DSc., PhD., Eng., Warsaw University of Technology, Faculty of Civil Engineering, ul. Lecha Kaczyńskiego 16, 00-637 Warsaw, Poland, e-mail: p.radziszewski@il.pw.edu.pl

${ }^{2}$ DSc., PhD., Eng., Warsaw University of Technology, Faculty of Civil Engineering, ul. Lecha Kaczyńskiego 16,00-637 Warsaw, Poland, e-mail: w.jackiewicz-rek@il.pw.edu.pl

${ }^{3}$ DSc., PhD., Eng., Warsaw University of Technology, Faculty of Civil Engineering, ul. Lecha Kaczyńskiego 16, 00-637 Warsaw, Poland, e-mail: m.sarnowski@il.pw.edu.pl

${ }^{4}$ DSc., PhD., Eng., Warsaw University of Technology, Faculty of Civil Engineering, ul. Lecha Kaczyńskiego 16,00-637 Warsaw, Poland, e-mail: m.urbanski@il.pw.edu.pl
} 
cement concrete slab with continuous steel reinforcement (continuously reinforced concrete pavement - CRCP).

There are currently ongoing studies on large format construction application of next-gen composite bars which are composed of, among others, basalt fibres. A new materialtechnological solution is the HFRP (Hybrid Fibre Reinforced Polymer) bar, where a portion of the basalt fibres is replaced with carbon fibres using resin binders. This creates an opportunity to create concrete elements with increased resistance to environmental aggression, while exhibiting good mechanical properties. This enables improvements on structural durability, which is particularly useful in the case of road structures.

This paper presents a material-technological and structural solution for a composite pavement, where a cement concrete slab with continuous HFRP bar reinforcement is used for strengthening. Based on laboratory tests, the serviceability of composite bars for reinforcing rigid pavement slabs was shown (strength tests for HFRP bars and their bond to concrete). Laboratory tests identified a possibility to strengthen asphalt pavements with a cement concrete slab with continuous HFRP next-gen hybrid bar reinforcement.

\section{ASPHALT PAVEMENT DAMAGE AND REPAIR METHODS IN CEMENT CONCRETE TECHNOLOGY}

Over the course of their lifespans, asphalt pavements undergo constant changes under the impact of loads from vehicle traffic and environmental factors. There are five fundamental forms of pavement damage [1]: permanent deformations in the form of washboarding and ruts, fatigue cracking, reflected cracking, induced thermal cracking, and surface damage.

There are many methods for repairing asphalt pavements via flexible technology [1]. In the case of damaged asphalt pavements where there's no identified need to replace the entire structure, the overlaid pavement technology - so-called "white-topping" ("white on black") - is used worldwide. Due to the specifics of the operation of an old asphalt pavement as a sub-base, a relatively thin covering cement concrete slab should be reinforced in a continuous manner. The use of continuous reinforcement is additionally justified in the case of insufficient load-bearing capacity of the lower located pavement or subbase.

No process cuts are made in a continuous reinforcement slab, whereas shrinkage cracking may appear at distances of $1 \div 3 \mathrm{~m}$, which are left unsealed [2,3]. Cracks have the ability to transfer 
large loads from traffic as a result of a phenomenon of inter-locking (wedging) of aggregate grains in the crack area. However, a crack width exceeding $0.6 \mathrm{~mm}$ may cause water penetration, contributing to the corrosion of steel reinforcement [3].

In the second half of the 20th century, composite materials based on FRP (Fibre Reinforced Polymer) were developed. In the beginning, these materials found their application in the defence and space industries while gradually expanding their application range to construction structures over the last 30 years. Fibres amount to $80 \%$ of a bar's volume with at least $20 \%$ being the matrix most frequently made of epoxy resins.

The most common causes for the destruction of concrete structures include reinforcement corrosion as a consequence of concrete carbonation, repetitive freezing/thawing cycles, and the impact of chlorides from the environment (e.g. as a result of using deicing agents). The main advantage of FRP bar reinforcement was considered to be the resistance to aggressive environmental factors, including chlorides. Road paving technology most frequently uses fibreglass bars in epoxy resin shielding as dowels and anchors for dowelled and anchored concrete slabs [4]. As shown in paper [5], dowels made of these bars with a diameter of $38 \mathrm{~mm}$ used in motorway construction exhibited properties comparable to steel dowels in epoxy resin shielding, with a diameter of $32 \mathrm{~mm}$. A similar project was implemented in the USA by the Ohio Department of Transportation. Dowels made of FRP bars (and steel dowels in resin shielding for comparison) were used for the construction of a concrete pavement of Interstate 77 in the years $1983 \div 85$. Clear corrosive damage of the steel bars was identified after 13 years of operation, while FRP bars did not exhibit traces of corrosion or deterioration of shear strength [4].

The material-process solution presented by the authors in the article involves using next-gen HFRP (Hybrid Fibre Reinforced Polymer) bars for continuous reinforcement of a road pavement concrete slab with improved resistance to chemical corrosion induced by the migration of water and deicing agents [4].

\section{PROPERTIES OF HFRP COMPOSITE BARS}

HFRP bars with basalt fibres are new in use with their mechanical properties not fully understood yet. Apart from basalt fibres ( $80 \%$ of the general fibre content), the HFRP bars also consist of carbon fibres (20\%) and a polymer matrix. The addition of carbon fibres favourably 
improves the tensile strength of the bars and causes an increase in the elastic modulus. HFRP bars, similar to FRP bars, are characterized by good resistance to the impact of alkali and acids [6].

\subsection{HFRP BAR TENSILE STRENGTH TEST}

Bars with diameters of 8 and $14 \mathrm{~mm}$ were tested. The geometric specification of the bars is shown in Table 1.

Table 1. Geometric specification of HFRP bar samples

\begin{tabular}{|c|c|c|c|c|c|}
\hline $\begin{array}{c}\text { Bar nominal } \\
\text { diameter } \\
{[\mathrm{mm}]}\end{array}$ & Size & Diameter & Circumference & Mass & Density \\
\cline { 2 - 6 } & $\begin{array}{c}d_{b} \\
{[\mathrm{~mm}]}\end{array}$ & $\begin{array}{c}c_{b} \\
{[\mathrm{~mm}]}\end{array}$ & $\begin{array}{c}m \\
{[\mathrm{~g}]}\end{array}$ & $\begin{array}{c}\gamma \\
{\left[\mathrm{g} / \mathrm{cm}^{3}\right]}\end{array}$ \\
\hline \multirow{2}{*}{8} & Mean values & 8.77 & 27.6 & 21.9 & 1.80 \\
\hline \multirow{2}{*}{14} & Standard deviation $\sigma$ & 0.05 & 0.16 & 0.13 & 0.01 \\
\cline { 2 - 6 } & Mean values & 15.06 & 47.3 & 64.6 & 1.81 \\
\cline { 2 - 6 } & Standard deviation $\sigma$ & 0.10 & 0.32 & 0.65 & 0.01 \\
\hline
\end{tabular}

The tensile test was carried out in accordance with the ACI 440.3R-04. The number of test specimens should not be less than five. Due to the anisotropy of the fibres, fastenings in the form of steel pipes at the ends of the tested bars were added (Fig. 1). The free space between the pipe and the bar was filled with a special binding material [6]. The view of an HFRP bar rupture location after a tensile test is shown in Fig. 2.

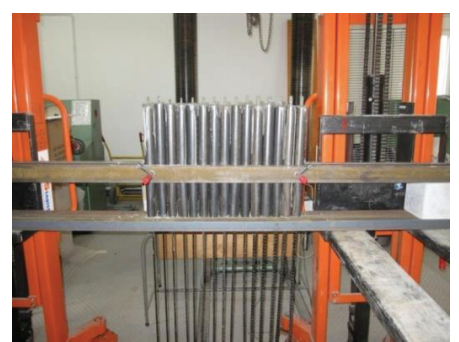

Fig. 1. A stand with unilaterally anchored HFRP bars

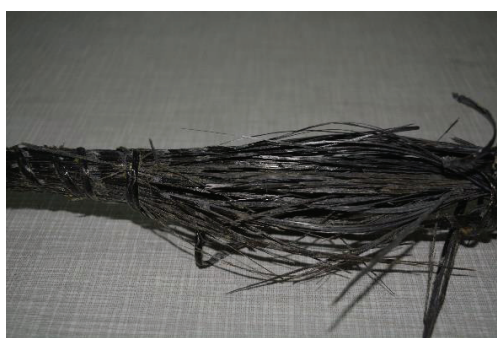

Fig. 2. $14 \mathrm{~mm}$ HFRP bars after rupture during a tensile test

Mean values of the ultimate tensile strength $f_{u}$, longitudinal modulus of elasticity $E_{L}$, and ultimate strain of HFRP bar $\varepsilon_{u}$ for six samples of HFRP bars are shown in Table 2. 
Table 2. HFRP bar tensile test results

\begin{tabular}{|c|c|c|c|c|c|}
\hline $\begin{array}{c}\text { Nominal } \\
\text { diameter } \\
{[\mathrm{mm}]}\end{array}$ & Size & $\begin{array}{c}\text { Maximum } \\
\text { load, } F_{u} \\
{[\mathrm{kN}]}\end{array}$ & $\begin{array}{c}\text { Ultimate tensile } \\
\text { strength, } f_{u} \\
{[\mathrm{MPa}]}\end{array}$ & $\begin{array}{c}\text { Ultimate } \\
\text { strain, } \varepsilon_{u} \\
{[\%]}\end{array}$ & $\begin{array}{c}\text { Longitudinal } \\
\text { modulus of } \\
\text { elasticity, } E_{L} \\
{[\mathrm{GPa}]}\end{array}$ \\
\hline \multirow{3}{*}{8} & Mean values & $\mathbf{7 2 . 8}$ & $\mathbf{1 2 0 4 . 0}$ & $\mathbf{1 . 5 2}$ & $\mathbf{6 7 . 9}$ \\
\cline { 2 - 6 } & Standard deviation $\sigma$ & 1.80 & 29.8 & 0.01 & 0.93 \\
\cline { 2 - 6 } & COV Variability & $2.48 \%$ & $2.48 \%$ & $0.82 \%$ & $1.37 \%$ \\
\hline \multirow{3}{*}{14} & Mean values & $\mathbf{1 8 3 . 6}$ & $\mathbf{1 0 3 0 . 9}$ & $\mathbf{1 . 5 2}$ & $\mathbf{7 0 . 1}$ \\
\cline { 2 - 6 } & Standard deviation $\sigma$ & 2.72 & 15.26 & 0.15 & 1.21 \\
\cline { 2 - 6 } & COV Variability & $1.48 \%$ & $1.48 \%$ & $10.05 \%$ & $1.73 \%$ \\
\hline
\end{tabular}

The results in Table 2 can be compared with typical data regarding steel bars, for which the yield point is approximately $500 \mathrm{MPa}$ (B500 steel), strain at yielding 0.0025 , and the elastic modulus $200 \mathrm{GPa}$.

Table 2 indicates that HFRP bars are characterized by favourable higher tensile strength and a greater strain range when compared to steel bars. An almost three times lower stiffness of HFRP bars (which can lead to greater deflection of concrete slabs of minor thickness) is worth noting.

\subsection{HFRP BAR CONCRETE BOND TESTS}

The bond beam test was carried out according to the PN-EN 10080 standard. In the course of the test, the slip of a stretched bar on both sides of a beam set was continuously recorded. During the tests, the load was increased monotonically, until reaching maximum slip. Figure 3 shows the central section of an HFRP bar during the test.

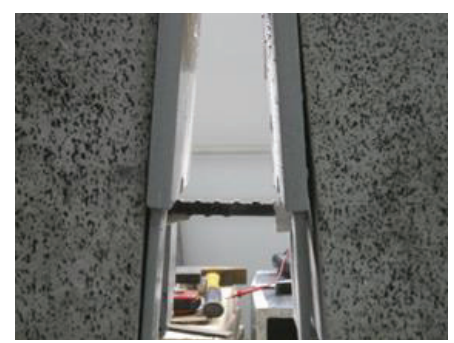

Fig. 3. Central section of an HFRP bar without bond to concrete

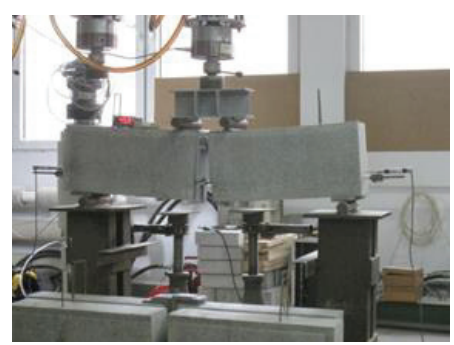

Fig. 4. Loss of bond of an HFRP bar in the final loading stage 
All tested bars exhibited a loss of bond stress in the final stage of loading, above $90 \% F_{u}$ (Fig. $4)$.

The bond strength of the HFRP bars assessed by the beam test method is shown in Fig. 5; Fig. 5a) shows the impact of bond stress $\tau$ on the slip $s$ for an HFRP bar, and Fig. 5b) the impact of bond stress $\tau$ on the slip $s$ for a steel bar.

a)

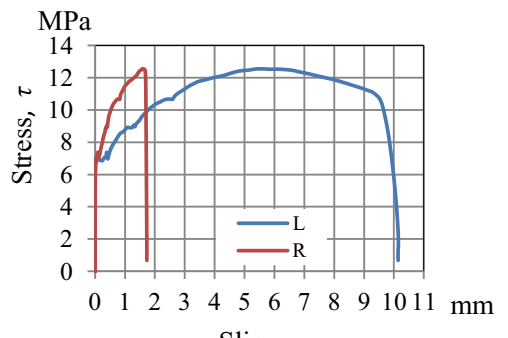

b)

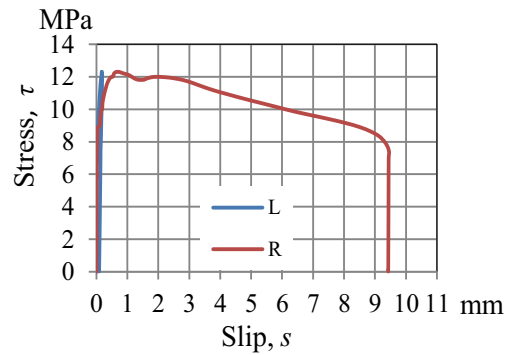

Fig. 5. The relationships between bond stress-slip: a) for a $14 \mathrm{~mm}$ HFRP bar (L - left slab, where slip appeared earlier than in the right slab - R), b) for a $20 \mathrm{~mm}$ steel bar (L - left slab, where slip appeared later than in the right slab - R)

The performed tests indicate that HFRP bars are characterized by better bond to concrete at increasing slip than steel bars. In the case of a steel bar sample, despite the fact that bond stress values were similar to those of HFRP bars, there was already a sudden loss of bond at a slip of $0.25 \mathrm{~mm}$ (for an HFRP bar, this value was five times higher). The equivalent diameter of an HFRP bar was $12.4 \mathrm{~mm}$ against a $20 \mathrm{~mm}$ diameter of a steel bar. It resulted in the bond surface of the steel bars being $62 \%$ higher than in the HFRP bars. Despite a significantly lower load resulting in loss of bond, bond stress was $44 \%$ higher in an HFRP bar than in comparable steel bars [7].

\section{FORTIFICATION OF ASPHALT PAVEMENT WITH CONCRETE SLAB}

A structure of experimental sections in the form of cement concrete slabs with continuous reinforcement arranged on old and damaged asphalt pavement was developed. Two $3 \mathrm{~m} \times 20$ $\mathrm{m} \times 20 \mathrm{~cm}$ slabs were made of $\mathrm{C} 35 / 45$ concrete and placed next to each other. One of the slabs was reinforced with HFRP bars, the second one, comparative, with steel bars matched on the 
basis of the Catalogue of Typical Rigid Pavement Structures (KTKNS) [2] and the requirements of the General Technical Specification (OST) D-05.03.04 [8].

A structural diagram of the experimental sections with concrete slabs with continuous reinforcement is shown in Fig. 6.

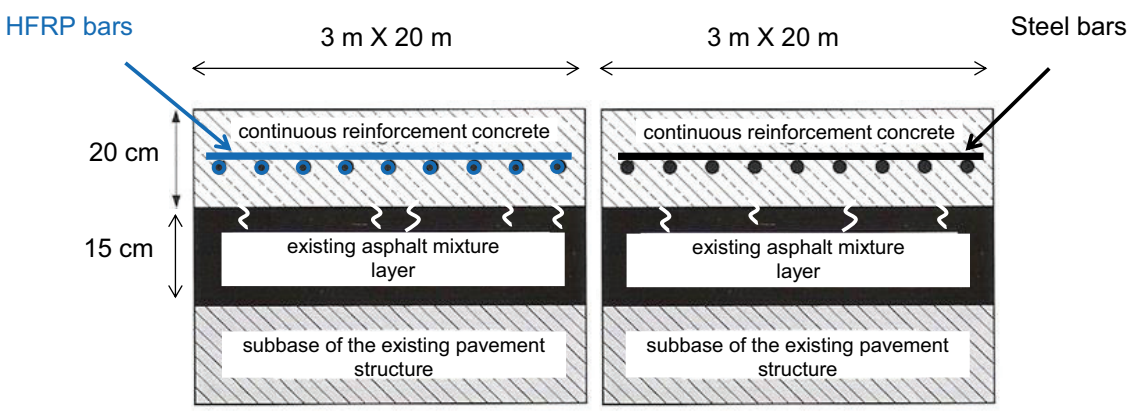

Fig. 6. The structural concept of an experimental section of cement concrete pavement with HFRP and steel (for comparison) bar continuous reinforcement

The following reinforcement patterns were used:

- reference concrete slab reinforced with B500 steel bars according to PN-EN 10080: Ø12 $\mathrm{mm}$ transverse bars with $70 \mathrm{~cm}$ spacing laid at an angle of $65^{\circ}$, and Ø20 $\mathrm{mm}$ longitudinal bars with $18 \mathrm{~cm}$ spacing with a $70 \mathrm{~cm}$ overlap (Fig. 7),

- concrete slab reinforced with HFRP (basalt-carbon) bars according to PN-EN with properties equivalent to the continuous steel reinforcement model: Ø8 $\mathrm{mm}$ transverse bars with $70 \mathrm{~cm}$ spacing laid at an angle of $65^{\circ}$, and $\varnothing 14 \mathrm{~mm}$ longitudinal bars with 18 cm spacing with a $70 \mathrm{~cm}$ overlap (Fig. 7).

The transverse bars are arranged in a skew (at an angle of $65^{\circ}$ ) so that transverse shrinkage cracks do not appear along the bars. 


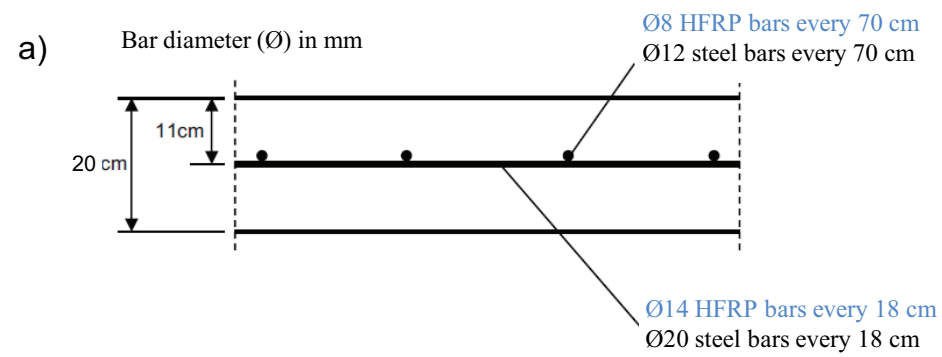

b)

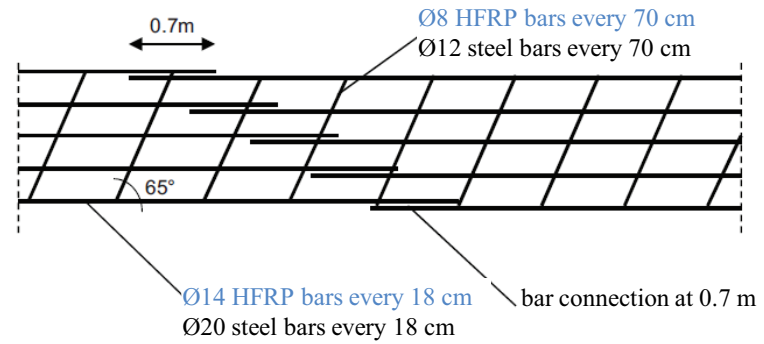

Fig. 7. Reinforcement pattern for concrete slabs with steel and HFRP bars according to KTKNS: a) slab layer cross-section, b) slab reinforcement top view

The equivalent diameter of the HFRP bars ( $\left.\phi_{\text {HFRP }}\right)$ used results from comparing the adequate diameters of the HFRP bars with the steel bars $\left(\phi_{S t e e l}\right)$ due to the tensile strength of the HFRP bars $f_{f}^{\text {HFRP }}$ and the yield strength of the steel bars $f_{y k}^{\text {Steel }}$. The HFRP bars are characterized by a tensile strength almost twice as high as that of steel bars. A comparison of adequate diameters may be presented with relationship (4.1).

$$
\phi_{\text {HFRP }}=\sqrt{\frac{f_{y k}^{\text {Steel }}}{f_{f}^{H F R P}}} \cdot \phi_{\text {Steel }}
$$

The calculations according to relationship (4.1) indicate that in terms of tensile strength a $Ø 14$ diameter (HFRP) is equivalent to a diameter of Ø20 (steel) and, accordingly, a Ø8 diameter (HFRP) corresponds to a Ø12 diameter (steel).

$\mathrm{C} 35 / 45$ concrete $\mathrm{R} / \mathrm{C}$ blocks $1.1 \mathrm{~m}$ high and $0.65 \mathrm{~m}$ wide were added onto both ends of the slabs (one at every end of the section). In cases of both the section with continuous HFRP bar 
reinforcement and the section with continuous steel reinforcement, $\mathrm{R} / \mathrm{C}$ block reinforcement was made using steel bars which can be bent on-site (as opposed to HFRP bars). It should be stressed that the reinforcement pattern for anchoring blocks is the same as for a slab with continuous HFRP reinforcement and a slab with steel bar reinforcement.

The arrangement of the anchoring $\mathrm{R} / \mathrm{C}$ blocks is shown in Fig. 8, and the reinforcement pattern of the blocks with steel bars is shown in Fig. 9.

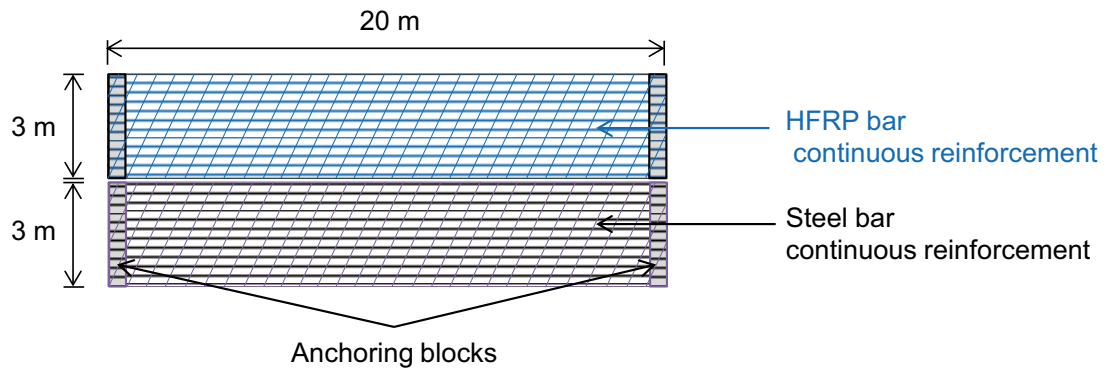

Fig. 8. Top view of experimental section slabs and of anchoring block reinforcement

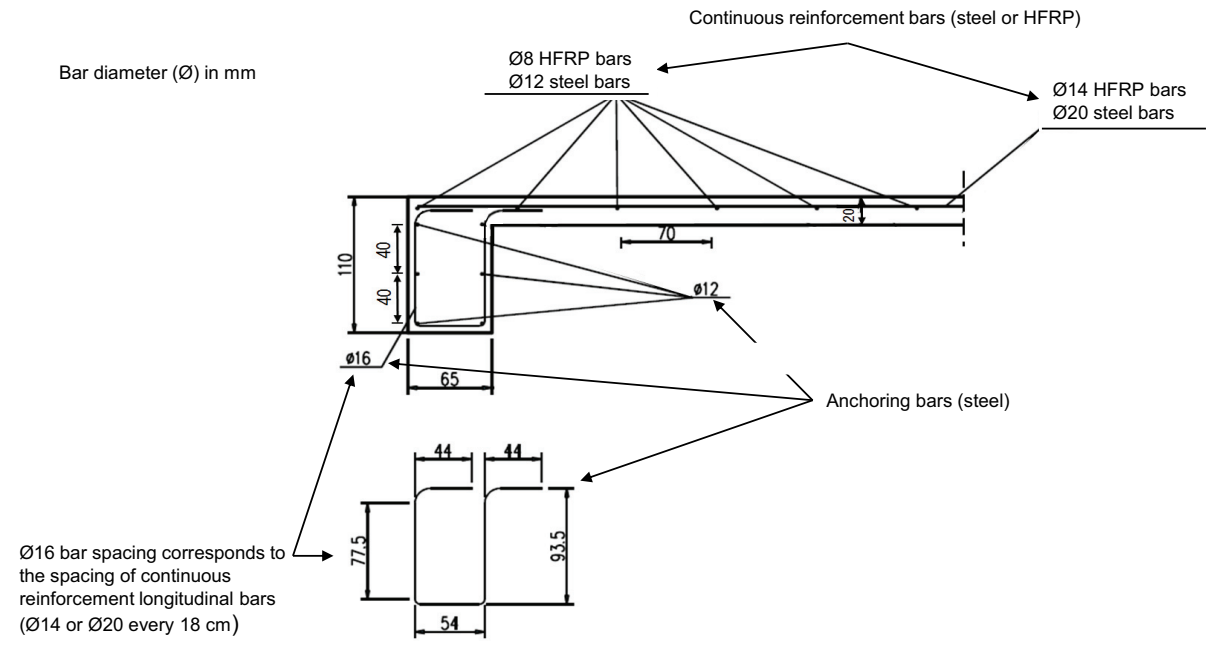

Fig. 9. Anchoring block reinforcement pattern 


\section{PROPERTIES OF CEMENT CONCRETE FOR PAVEMENT REINFORCED WITH HFRP BARS}

The concrete mix for the road pavement of the experimental section was selected based on the following design assumptions:

- concrete for the top pavement layer - requirements regarding concrete mix aeration (aerated concrete with a total mix air content of $5 \div 6 \%$ and appropriate structure, i.e., appropriate pore size and arrangement) and set concrete properties according to the General Technical Specification (OST) for the performance and acceptance of work associated with creating a cement concrete pavement D-05.03.04 [8],

- concrete strength class C35/45 as per PN-EN 206:2014,

- exposure class XF3 and the resulting frost resistance class FT1 as per PKN-CEN/TS EN 12390-9,

- traffic category KR5 $\div$ KR7 as per KTKNS [2],

- maximum aggregate dimensions of $\mathrm{D}_{\max } 8 \mathrm{~mm}$,

- the amount of aeration and liquefying admixtures in the concrete composition as per the manufacturer's guidelines found in the material sheet for obtaining parameters required by OST.

The adopted scope of testing included checking the properties of the concrete mix (consistency, specific density, total air content) and tests covering set concrete (compressive strength, tensile strength at splitting, bending strength, shrinkage) as well as features typically associated with concrete durability (absorbability, water penetration depth, F150 frost resistance).

\subsection{MATERIALS AND RESEARCH METHODOLOGY USED FOR CEMENT CONCRETE DESIGN}

CEM I 42.5R Portland cement was used as a binder for the concrete mixes. Prior to commencing the concreting process, the cement was tested as per the requirements of PN-EN 197-1: 2012E. In all concrete mixes, the fine aggregate was $0 / 2$ sand and the coarse aggregate - basalt of $2 / 8$ and 5/8 mm fractions. Tap water meeting the requirements of PN-EN 1008:2004P was used in the concrete mixes. In order to achieve the assumed concrete mix consistency, a superplasticizer (based on magnesium lignosulfonate) meeting PN-EN 934-2 standards was used. Concrete mix 
aeration at a level of $5 \div 6 \%$ was achieved through an aerating admixture (based on synthetic tensides), according to PN-EN 934-2.

The following tests of the concrete and concrete mix were performed:

- consistency with the Ve-Be method as per PN-EN 12350-3,

- aeration with the pressure method as per PN-EN 12350-7,

- compressive strength of samples after 2 and 28 days of curing, as per PN-EN 12390-3,

- concrete bending strength after 28 days of curing, as per PN-EN 12390-5,

- concrete tensile strength at splitting PN-EN 12390-6,

- internal frost resistance of concrete as per PN-88/B-06250-frost resistance rating F150,

- scaling resistance in the presence of salt PKN-CEN/TS EN12390-9,

- concrete absorbability as per PN-88/B-06250,

- water penetration depth as per PN-EN 12390-8,

- concrete shrinkage as per PN-B-06714-23.

\subsection{CONCRETE AND CONCRETE MIX PROPERTIES}

The quantitative selection of the concrete mix involved the optimization of the number of selected ingredients in terms of obtaining the assumed properties of both the concrete and the concrete mix for reinforced pavement which correspond to the adopted assumptions. Ultimately, concrete compositions with a water-cement (w/c) coefficient of 0.35 were created. The recipes kept to a fixed amount of cement, fine and coarse aggregate, water, and liquefying admixture. The recipes differ only in terms of the admixture guaranteeing appropriate aeration (this paper presents only these) where admixture aeration was $6.5 \%$ and $5 \%$.

Strength properties of the aerated concretes where the total content of air in the mixture was $6.5 \%$ and $5 \%$, respectively, are shown in Table 3. The tested concretes achieved tensile strengths satisfying the requirements of the double criterion of conformity as per the PN-EN 206 standard for the assumed compressive strength class of C35/45.

The development of compressive strength $r$, defined as a ratio of compressive stress of a sample after 2 days $\mathrm{f}_{\mathrm{cm} .2}$ of curing to the compressive strength of concrete after 28 days of curing $\mathrm{f}_{\mathrm{cm} .28}$ was favourable in all tested concretes, according to PN-EN 206 fast, and amounted to 0.76 and 0.91 in the cases of concretes with $6.5 \%$ and $5 \%$ aeration, respectively. 


\begin{tabular}{|lc|c|c|}
\hline \multirow{2}{*}{ Tested feature } & \multicolumn{2}{|c|}{ Total air content in a concrete } \\
& & $\mathbf{6 . 5 \%}$ & $\mathbf{5 \%}$ \\
\cline { 3 - 4 } & & 37.62 & 48.81 \\
\hline Compressive strength, $\mathrm{f}_{\mathrm{cm} 2},[\mathrm{MPa}]$ & standard deviation, $[\mathrm{MPa}]$ & 0.06 & 0.12 \\
\hline & & 49.59 & 53.21 \\
\hline Compressive strength, $\mathrm{f}_{\mathrm{cm} 28,},[\mathrm{MPa}]$ & standard deviation, $[\mathrm{MPa}]$ & 1.13 & 0.21 \\
\hline & & 3.30 & 4.12 \\
\hline Tensile strength, $\mathrm{f}_{\mathrm{tm} 28},[\mathrm{MPa}]$ & standard deviation, $[\mathrm{MPa}]$ & 0.34 & 0.10 \\
\hline & & 5.89 & 6.10 \\
\hline Bending strength, $\mathrm{f}_{\mathrm{fm} 28},[\mathrm{MPa}]$ & standard deviation, $[\mathrm{MPa}]$ & 0.09 & 0.11 \\
\hline
\end{tabular}

According to the General Technical Specification, concrete bending strength on day 28 of curing, calculated as an average for three samples, should not be lower than $5.5 \mathrm{MPa}$ (KR5 $\div \mathrm{KR} 7)$. The formulated concretes meet these requirements in excess, but only the concrete with $5 \%$ aeration met the criterion for this traffic category, regarding the tensile strength - the average result from 3 samples is equal to at least $3.7 \mathrm{MPa}$.

The aerated concrete (5\%) was tested for temperature resistance through 150 freezing and thawing cycles. A frost resistance test was conducted after 28 days of sample curing in a climatic chamber (air temperature $20 \pm 2^{\circ} \mathrm{C}$, relative humidity $>95 \%$ ). When comparing that feature with the requirements of the General Technical Specification, the percentage decrease in the weight of concrete samples subjected to freezing/thawing cycles, relative to pre-test weight, should not exceed 5\%. The tested concrete also met this requirement (Table 4). Also, in the case of a decrease in concrete strength after freezing/thawing, the concrete recorded a decrease of just below 4\%, hence, the required F150 frost resistance can be confirmed.

Table 4. Frost resistance results for F150 concrete as per PN-88/B-06250

\begin{tabular}{|c|c|}
\hline Tested feature & $\begin{array}{c}\text { Determination } \\
\text { result }\end{array}$ \\
\hline Average weight loss, [\%] & $\mathbf{1 . 3}$ \\
\hline $\begin{array}{c}\text { Average compressive strength of samples after 150 } \\
\text { freezing/thawing cycles, [MPa] }\end{array}$ & 51.44 \\
\hline Standard deviation, [MPa] & 0.82 \\
\hline Average compressive strength of witness samples, [MPa] & 53.44 \\
\hline Standard deviation, [MPa] & 1.99 \\
\hline Average loss of compressive strength, [\%] & $\mathbf{3 . 7 4}$ \\
\hline
\end{tabular}

The concrete was also subjected to a scaling resistance test in the presence of salt, as per the recommendations of a "slab test" in the PKN-CEN/TS EN 12390-9. After 28 days of curing, the samples were placed in a freezing chamber for 58 freezing/thawing cycles; intermediate measurements, after 14 and 28 days, were also performed. The results of all calculations 
regarding flaking fell within the range permitted for the FT1 category of resistance to freezing/thawing in the presence of salt (average mass loss value $m_{28}<1.0 \mathrm{~kg} / \mathrm{m}^{2}$ and each individual result under $1.5 \mathrm{~kg} / \mathrm{m}^{2}$ ), and even met the requirements of the FT2 category (requirement below $0.5 \mathrm{~kg} / \mathrm{m}^{2}$, average mass loss value $\mathrm{m}_{58}$ below $1.0 \mathrm{~kg} / \mathrm{m}^{2}$ and loss degree $\mathrm{m}_{56} / \mathrm{m}_{28}$ required below 2$)$.

The cement concrete formulated exhibited surface frost resistance in the presence of defrosting agents and may be used for upper pavement layering [8]. Similarly, in the case of resistance to the impact of water under constant $0.5 \mathrm{MPa}$ pressure, sample water penetration depths during the test were not too high and did not exceed $2 \mathrm{~cm}$. Therefore, they meet the requirement set for pavement concretes.

All conducted tests confirm the properties required of cement concretes for road pavements.

\section{Conclusions}

Damaged asphalt pavements may be fortified with a cement concrete slab with continuous reinforcement of next-gen HFRP bars. Although the average cost of HFRP bars is about $15 \%$ higher than that of steel bars, the next-gen composite bars are characterized by resistance to environmental aggression while maintaining good strength properties. The conducted laboratory tests indicate that HFRP bars are characterized by favourably higher tensile strength, wider strain range, and better bar-concrete bonds when compared to steel bars. These factors create an opportunity for fabricating concrete elements with increased durability, which is particularly important in the case of road structures. A structural concept of an experimental section of cement concrete pavement with HFRP bar continuous reinforcement was presented. A designed and constructed experimental section of pavement with a concrete slab reinforced with HFRP bars confirms the possibility of implementing composite reinforcements of significant dimensions on a real-world scale. Planned field tests of the pavement, laboratory tests of samples collected from the pavement, and monitoring of a section loaded with heavy traffic will enable complete verification of the strengthening properties of concrete pavement reinforced with next-gen composite bars. The newest experiences collected during construction, monitoring, and testing of the experimental sections will be presented in Part II of this research.

\section{ACKNOWLEDGEMENTS}


The tests were conducted within a grant from the National Centre for Research and Development Applied Research Programme (NCBR:PBS3/A2/20/2015) titled "Innovative hybrid, composite FRP reinforcement for infrastructural structures with improved durability".

\section{REFERENCES}

[1] J. Piłat, P. Radziszewski, Nawierzchnie asfaltowe [Asphalt pavements]. Wydawnictwa Komunikacji i Łączności, Warszawa 2010.

[2] Katalog Typowych Konstrukcji Nawierzchni Sztywnych [Catalogue of Typical Rigid Pavement Structures], Politechnika Wrocławska 2014.

[3] J. R. Roesler, J. E. Hiller, A. S. Brand, Continuously reinforced concrete pavement manual. Guidelines for Design, Construction, Maintenance, and Rehabilitation. U.S. Department of Transportation, Federal Highway Administration (FHWA), August 2016.

[4] S. Rizkalla, M. Dawood and M. Shahawy, FRP for Transportation and Civil Engineering Infrastructure: Reality and Vision, Proceedings of the 85th Annual Transportation Research Board (TRB) Meeting, Washington, D.C., January 22-26, 2006.

[5] D. Eddie, A. Shalaby and S. Rizkalla, Glass Fiber-Reinforced Polymer Dowels For Concrete Pavements. ACI Structural Journal, 98, (2001), pp. 201-206.

[6] M. Urbański, A. Łapko, Effectiveness of flexural basalt reinforcement application in R/C structures, Monograph Edited by Stanisław Fic: Modern Materials, Installations and Construction TechnologiesBREST - ODESSA - SIMFEROPOL - BIALYSTOK - BIALA PODLASKA, Biała Podlaska2013, pp. 112 -123.

[7] A. Garbacz, M. Urbański, A. Łapko, BFRP bars as an alternative reinforcement of concrete structures Compatibility and adhesion issues. Advanced Materials Research (1129), 2016, pp. 233-241.

[8] Ogólne Specyfikacje Techniczne, D-05.03.04, Nawierzchnie betonowe [Concrete pavements], GDDKiA, Warszawa, 2014. 